\title{
Low emission hell in Polish cities - how to get rid of it through technical solutions applied in single family houses?
}

\author{
Dominika Dawiec ${ }^{1}$, Grzegorz Ginda ${ }^{2}$ \\ ${ }^{1}$ Faculty of Geology, Geophysics and Environmental Protection, \\ AGH University of Science and Technology, Cracow, Poland \\ ${ }^{2}$ Faculty of Management, AGH University of Science and Technology, Cracow, Poland \\ E-mail: 'domiwos@agh.edu.pl (correspondingauthor)
}

\begin{abstract}
Air in Polish cities belongs to the most polluted in Europe due to numerous causes e.g. high volume of road traffic, inefficient road infrastructure, the utilisation of environment unfriendly vehicle propulsion. However, the culmination of poor air problem noticeably occurs in winter as a result of the need for supplying buildings with a great amount of heat energy to defy influence of severe climate conditions. One of the most important causes for such situation deals with the application of solid fuel-based heat sources for heating buildings. The widespread burning of cheap coal in outdated home stoves results in producing smoke rife that includes carcinogens like dioxins and benzo(a)pyrene, as well as the small sooty particles that are strongly linked to heart disease, respiratory diseases and other sickness. Economical and social reasons make the application of such energy sources popular among single family house owners. Popularity of single family houses in Polish cities thus makes air pollution problem even more serious. Therefore, the effectiveness of selected solutions which would hopefully help to limit low pollution emission are discussed in the paper. They correspond well to current Polish government air improvement initiatives towards the improvement of air quality in Polish cities.
\end{abstract}

Keywords: air quality, low pollution emission, limitation, heating, single family house.

\section{Introduction}

Quality of life of residents and people who simply work in a city depends on diverse issues. Some of the issues play fundamental role because they provide necessary conditions for supporting life in a city. This is undoubtedly the case of environmental issues and most notably - the case of city air quality.

Permissible limits of air pollutants are often significantly exceeded in Polish cities. As a result Polish cities used to be reported as the most polluted areas in Europe and maybe in the world. Poor air quality negatively influences both health of people and natural environment in a city. Moreover, the severe adverse effects of air quality often occur in far future. Poor air quality belongs, therefore, to the most critical problems that obstruct living and working in Polish cities.

There are different causes of poor air quality in Polish cities. For example, the largest Polish cities e.g. Warsaw or Cracow, suffer from pollutants resulting from enormous road traffic while road transit is responsible for poor air quality in smaller cities. This is why some official programmes for improving air quality are proposed. For example, Polish government is now involved in limiting bad influence of road traffic on air quality by means of e-mobility programme for years 2016-2025 (Polish Government, 2016). Local authorities also develop some initiatives that are aimed at limiting road traffic in city centres (Magical Cracow, 2016). For example, traffic organisation changes are introduced and free urban transportation services are offered for citizens.

However, data gathered by air pollution monitoring systems in Polish cities (Magical Cracow, 2016) indicate that air quality is mainly endangered by seasonal low pollution emission. This is because of a need for providing considerable amount of heat energy for heating houses in colder months from October to April.

The application of district heating systems for providing heat energy allows to control pollutant emissions. District heating systems are nevertheless only rarely applied to provide heat for single family houses in Poland. This is a shame as such houses are very popular - especially amongst citizens living in suburbs of large Polish cities, Polish villages and Polish small towns. Most single family owners are forced, therefore, to provide heat energy themselves. Financial situation of an ordinary Polish family isn't still good today even despite the successful introduction and 
implementation of several social programs by current Polish government (Concise yearbook 2018, 2019). This is because it will rather take a considerable amount of time to stabilize financial situation of Polish families in a long run. Moreover, bad financial situation of the families often results in poor technical state of the houses and their equipment.

Economical and social disparities as well as adverse habits of the owners result in widespread use of outdated boilers and environment-unfriendly solid fuels e.g. hard coal or wood. Poor technical state of the houses often contributes to excessive pollution of air. Such frequent practices make the residents in single family houses especially responsible for poor air quality in Polish cities. The discussion of remedies which would help in effective and immediate suppression or even the elimination of low pollution emission from single family houses is therefore justified and welcome.

Possible environmentally friendly improvements in a single family house heating can be perceived from two different pespectives. The first perspective is devoted to technology. The possibility of successful application of environmentally friendly technology usually depends, however, on ability to spend a conderable amount of money. This is why a need for using financial perspective while analysing suitability and practical availability of possible technologies is also demonstrated. The financial perspective is especially important in the case of Polish families. This is because considerable number of them exercise the problem of energy poverty which is caused by limited financial capability of households to afford enough spendings to satisfy actual energy supply needs (Birol, 2007; Primc, Slabe-Erker, \& Majcen, 2019).

Practical availability of sample remedies for limiting or even eliminating low pollution emissions from a Polish single family house equipped with an outdated and manually controlled hard coal-fueled boiler is finally discussed in the paper. Both technological and financial perspectives are considered with this regard. Therefore, the rest of the paper is structured as follows. The second section is devoted to the presentation of sample remedies for environmentally friendly improvement of heating systems in Polish single family houses. Practical availability of the remedies is discussed in the third section. General conclusions about practical availability of the remedies are finally drawn in the last section.

\section{Sample remedies}

It was assumed that the needed level of heat power in considered single family house amounts to $20 \mathrm{~kW}$. This is why only remedies which allowed to provide such heat power level were considered. The remedies represent two basic approaches. The first approach deals with the improvement of existing heating system. Two options are considered in this regard, namely:

- boiler furnace upgrade - Cf (Clean heating, 2018),

- Polish external smoke electro-filters - Ce (Wesołowska, 2018).

Note that the former option represents internal improvement while the latter represents external improvement of an existing heating system.

The second approach deals with the complete replacement of heat source by the application of:

1. A boiler using the following fuel:

a. Hard coal (C5 - class 5 boiler aka eco-design boiler).

b. Natural gas $(\mathrm{Ng})$.

c. Biomass ( $\mathrm{Bm}$ - the application of discarded wood, sawdust etc.).

2. An advanced renewable energy-based system, namely:

d. Split external air-to-water heat pump (Hp) (Hewalex, 2019).

e. System consisting of a biomass boiler and solar collectors (Bs).

f. System consisting of a heat pump and solar collectors (Hs).

The following attributes are considered to describe the improvements:

- required basic cost of investment (I), operation (O), and utilization (U),

- generated air pollution (A) and waste (W),

- contribution to national energy safety (E),

- inherent durability (D) which results from current anti-smog law regulations,

- usage comfort (C),

- a need for auxiliary power supply (S), and a need for major technical adjustments to other parts of heating system, existing building envelope etc. (T).

Considered set of attributes makes it possible to assess considered improvement alternatives from a point of view of their perspective users $(\mathrm{O}, \mathrm{U}, \mathrm{D}, \mathrm{C}, \mathrm{S}, \mathrm{T})$ as well as from perspective of other stakeholders e.g. immediate neighbours, society, local and home authorities, governmental and local institutions, environmentalists, economists etc. $(A, W, E)$. 
Advantages and disadvantages of considered options are finally illustrated in Table 1 where plus and minus signs correspond with advantages and disadvantages, respectively. A lack of any sign expresses a fact that it isn't clear whether a state of a given attribute is undoubtedly advantagous or disadvantageous. Note that applied data result from own experience and extensive web research.

Table 1. Atributes of options (source: own work)

\begin{tabular}{|l|c|c|c|c|c|c|c|c|}
\hline \multicolumn{1}{|c|}{ Attribute } & $\mathrm{Cf}$ & $\mathrm{Ce}$ & $\mathrm{C} 5$ & $\mathrm{Ng}$ & $\mathrm{Bm}$ & $\mathrm{Hp}$ & $\mathrm{Bs}$ & $\mathrm{Hs}$ \\
\hline Investment costs (I) [PLN] & $1,500.00$ & $4,000.00$ & $7,000.00$ & $3,000.00$ & $4,000.00$ & $30,000.00$ & $25,000.00$ & $46,000.00$ \\
\hline Operation costs (O) & - & - & - & - & - & + & - & + \\
\hline Utilization costs (U) & + & - & - & - & - & - & - & - \\
\hline Air pollution (A) & + & - & + & + & + & + & + & + \\
\hline Waste generation (W) & - & - & - & + & - & + & - & + \\
\hline Energy safety (E) & + & + & + & - & + & + & + & + \\
\hline Durability (D) & - & - & + & + & + & + & + & + \\
\hline Comfort (C) & - & - & & + & & + & & + \\
\hline Auxiliary power supply (S) & + & - & - & - & - & - & - & - \\
\hline Technical adjustments (T) & + & + & & & & - & - & - \\
\hline
\end{tabular}

\section{Practical availability of alternatives}

\section{Comparison of alternatives}

Data gathered in Table 1 confirm that considered alternatives for replacing existing solutions differ a lot in provided advantages and disadvantages. They may be nevertheless divided into several groups according to single attributes or groups of attributes. Let's apply single attributes at first to identify specific groups of alternatives. According to base investment cost there are two groups of options:

1. The alternatives which deal with enhancement of heating systems using solid fuels and natural gas (Cf, Ce, C5, Bm, Ng) - investment costs: 1,500.00 PLN - 7,000.00 PLN (about 350.00 EUR - 1650.00 EUR as for the 20 th of March 2019 when 1 PLN = 4.30 EUR).

2. More complex alternatives which exploit different energy sources ( $\mathrm{Hp}, \mathrm{Bs}, \mathrm{Hs})$ - investment cost reaching several hundreds PLN.

Operation cost attribute makes it possible to isolate two undoubtedly advantageous alternatives (Hp, Hs). Their common feature deals with the application of heat pump technology. The application of utilization cost attribute results in the only one advantageous alternative, namely standard hard coal boiler with enhanced furnace (Cf). All alternatives but a standard hard coal boiler with smoke electro-filters (Ce) prove to be advantageous with regard to the elimination of low pollution emission. Every alternative that doesn't use solid fuel $(\mathrm{Ng}, \mathrm{Hp}, \mathrm{Hs})$ is advantageous with regard to waste generation. The application of easily and locally available fuel results in higher alternative assessment according to contribution to national energy safety. This is why only natural gas boiler comprises a disadvantageous alternative with this regard. Only enhanced outdated hard coal boilers (Cf, Ce) are susceptible to insufficient durability and a lack of usage comfort. All other alternatives are durable enough. Real comfort of use is provided by natural gas boilers $(\mathrm{Ng})$ and combined heating systems $(\mathrm{Hp}, \mathrm{Hs})$. Automation of device control aids comfortable use of hard coal class 5 boilers (C5) and biomass boilers (Bm). However, comfort is finally hindered by specific manual operations like fuel supply and fuel loading into a device. Majority of boilers need auxiliary power supply for the automation of operations and propulsion of additional devices e.g. smoke electro-filters. A lack of a need for auxiliary power supply is kept only in the case of outdated boilers with updated furnace (Cf). Possible obligation to adjust other parts of heating system and building envelope to requirements associated with an alternative is very important as it may considerably influence final investment costs of application of that alternative. This is undoubtedly the case of the application of expensive devices like heat pumps ( $\mathrm{Hp}, \mathrm{Hs})$ and the combination of biomass boiler and solar collectors (Bs). Standalone biomass boilers, hard coal class 5 boilers, and natural gas boilers (Bm, C5, Ng) may also become susceptible to the effects of such a kind.

A variety of registered investment costs (I) and a fundamental role of this attribute with regard to the assessment of affordability of the alternatives suggest to abandon this attribute while comparing the alternatives. It proves out that there no significant differences between some alternatives. The main reason for this is the application of a fuel or other energy source of the same kind like in the case of hard coal class 5 boiler (C5) and biomass boiler (Bm) as well as in the case of heat pump-based alternatives ( $\mathrm{Hp}, \mathrm{Hs}$ ). A lack of significant differences between alternatives may directly suggest the choice of an alternative that is simply cheaper in the context of investment costs. 
Some alternatives dominate over other alternatives in sense of Pareto efficiency. This is because they are better in some attributes and at least similar in other attributes. Domination of alternatives may be illustrated by means of a dominance (di)graph. Figure 1 llustrates dominance of alternatives while considering: user perspective-related attributes $\mathrm{O}, \mathrm{U}, \mathrm{D}, \mathrm{C}, \mathrm{S}, \mathrm{T}$ only (the leftmost digraph) or other stakeholders' perspective-related attributes A, W, E only (the rightmost digraph). Note that both dominance digraphs clearly indicate dominance hierarchy. Each level of the hierarchy is composed by alternatives which don't dominate each other. The topmost level alternatives dominate other alternatives. Alternatives in each other level are dominated by some alternatives which occupy higher hierarchy levels. Dominance hierarchy thus expresses hierarchical preference of alternatives. Topmost hierarchy level contains the most preferred alternatives while the bottommost level consists of the least preferred alternatives.
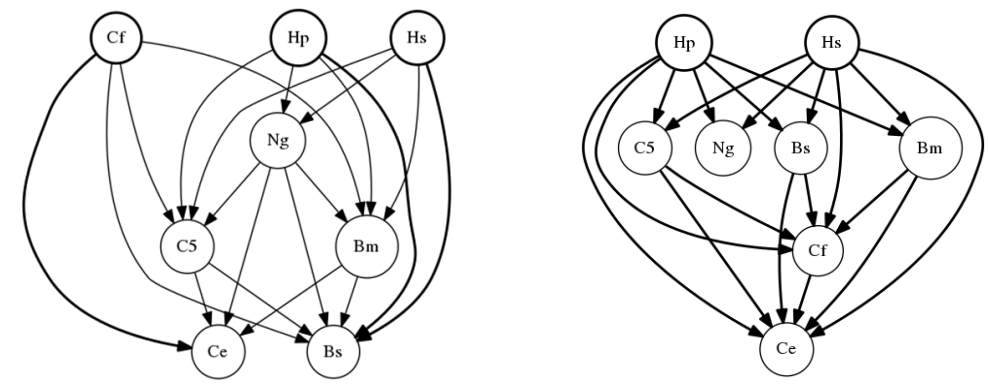

Figure 1. Dominance digraphs for considered alternatives (source: own work)

Surprisingly, complex alternatives Hp and Hs don't dominate a simple improvement - the update of an existing hard coal boiler (Cf) in the case of user perspective. Moreover, the latter alternative dominates one of more advanced alternatives, namely hard coal class 5 boiler (C5). The topmost hierarchy level is thus occupied by three globally dominating alternatives - $\mathrm{Cf}, \mathrm{Hp}$ and $\mathrm{Hs}$. A single alternative - natural gas boiler ( $\mathrm{Ng}$ ) comprises the first intermediate level while two other alternatives - hard coal class 5 boiler (C5) and biomass boiler (Bm) - comprise the second intermediate level. The remaining two alterantives - a hard coal boiler with smoke electro-filters (Ce) and complex of biomass boiler and solar collectors (Bs) - belong to the bottommost level.

The application of other stakeholders' perspective results in a simpler dominance hierarchy. This time only two complex alternatives which use heat pump (Hp, Hs) prove to be globally dominating alternatives. Two bottommost hierarchy levels consist of the least advanced alternatives - a head coal boiler with enhanced furnace (Cf) and a hard coal boiler with smoke electro-filters $(\mathrm{Ce})$. They are dominated by globally dominating alternatives and the remaining alternatives - $\mathrm{C} 5, \mathrm{Ng}, \mathrm{Bm}, \mathrm{Bs}-$ which occupy the only intermediate level.

The notion of dominance is based on the attributes of possible alternatives but investment costs in our case. The attribute of investment costs may be applied, therefore, as a discriminating tool which provides necessary means to identify the best alternatives for each dominance hierarchy level.

\section{Individual investments}

Let's concentrate on the case of individual investments into more friendly building heating by single house users themselves. Note that final recommendation of optimal investment depends on user's financial capability to bear necessary investment costs. It is evident from the leftmost dominance hierarchy presented in Figure 1 and data presented in Table 1 that a user may afford one of globally dominating alternatives - a boiler furnace update (Cf) - at a relatively small amount of money $(1,500.00 \mathrm{PLN}=350.00 \mathrm{EUR})$ will do. This is good news for poor single family households. Such households prevail amongst air polluters in Poland. So, this is also good for the efforts of improve air quality. The other globally dominating alternatves $-\mathrm{Hp}$ and $\mathrm{Hs}$ - neverthless would remain beyond reach of even relatively rich people. This is because the alternatives require the application of adjustments to building envelope and other parts of existing heating systems. And adjustments of such a kind are costly. Actual costs of such adjustments usually exceed 20,000.00 PLN (4,700.00 EUR). So, reliable application of Hp and Hs means spending about $50,000.00$ PLN (11,700.00 EUR) at least.

There may occur the case, however, when the cheapest dominating alternative (Cf) wouldn't be attainable e.g. due to technical reasons or wouldn't be acceptable due to poor durability. Dominance alternative digraph suggests the application of natural gas boiler $(\mathrm{Ng})$ in such the case. Note that this is also the second cheapest alternative as its application results in investment cost at 3,000.00 PLN (700.00 EUR) level. So, this is the natural choice with regard to investment cost criterion.

Density of local area natural gas distribution networks is very high in Poland as fuel of such a kind is popular amongst Polish households because of cooking purposes. The application of natural gas may be nevertheless hindered in a peculiar case due to a lack of adjacent local area natural gas network. In such the case the application of alternatives which occupy the foremost dominance hierarchy level would be considered, namely a hard coal class 5 boiler (C5) and a biomass boiler (Bm) which use fuels which are commonly available in Poland. Considerably higher 
investment cost of a former type of boiler (7,000.00 PLN i.e. 1700.00 EUR) makes the choice of a biomass boiler evidently better as its investment costs (4,000.00 PLN i.e. 950.00 EUR) are considerably lower. Note, however, that local Polish market of hard coal class 5 boilers currently offers rather complex and thus expensive devices due to swift implementation of demanding requirements with regard to the application of coal to heat buildings (CR (EU) $2015 / 1189,2015)$. It expected in the near future, therefore, that the development of the market would constantly wider the available offer with regard to both complexity and resulting investment costs of devices. So, more cheaper and thus more competitive hard coal class 5 boilers are expected to be available soon.

Superiority of natural gas boliers and common availability of fules for biomass boilers make them evidently better choices than the cheapest alternative in the bottommost dominance hierarchy level - a hard coal boiler with electro-filters (Ce) which is available at a similar investment cost level (4,000 PLN i.e. 950.00 EUR). Similar costly adjustments are needed for them as in the case of Hp and Hs, however, to exploit their whole potential. The adjustments of such a kind would render them noncompetitive to Ce alternative.

It may be finally concluded that there are building heating options affordable for single family house owners that would make considerable low pollution emission reduction possible. Both low budget, however rather less durable, options like update of furnace in existing hard coal boiler (Cf) as well as more durable but more expensive natural gas boiler $(\mathrm{Ng})$ or biomass bolier $(\mathrm{Bm})$ may be recommended in this regard. Especially the latter alternatives seem more attractive as they may encourage and motivate users to involve in environment-friendly investments with regard to the reduction in demand for energy by means of the introduction of meaningful enhancements into building envelope or other parts of building heating system. Considerble air quality improvements may be thus expected by spending 1,500.00 PLN - 4,000.00 PLN per a single house. Even such, relatively low, spending nevertheless poses a problem to majority of Polish households due to their poor economic situation. This is why investments in environmentally friendly heating systems are still hindered amongst majority of single family house households. Financial support is offered, therefore, to single family owners to help them in making heating of their houses environmentally friendly.

\section{Supported investments}

There are different offers of financial support for investments in environmentally friendly heating of single family houses. Both governmental agencies and local authorities are involved in an aid of such a kind in Poland. These parties are obliged to assist citiziens in satisfying more and more demanding environmental and energy saving goals. This is why their support offer strongly prefers comprehensive enhancements which are related to the both aforemetioned goals. Required enhancements are thus not limited to the replacement of a source of heat only but they always cover all heating system and building components. This is why the offered support usually applies to very costly investments only.

The effects of the aforementioned goals are expressed well by the rightmost dominance hierarchy in Figure 1. It proves that there are two dominating alternatives - Hp and Hs. As it was shown already, overall costs of their application would usually start from 50,000.00 PLN and 66,000.00 PLN (11,700.00 EUR - 15,400.00 EUR), respectively. The upper intermediate level of dominance hierarchy is made up by the alternatives whose complex investment costs significantly exceed several thousands PLN - 23,000.00 PLN (5,400.00 EUR), 24,000.00 PLN (5,600.00 EUR), 27,000.00 PLN (6,300.00 EUR), and 45,000.00 PLN (10,500.00 EUR) for Ng, Bm, C5 and Bs alternative, respectively. The investment costs for furnace upgrade (Cf) and electriofilters application (Ce) are the same as before due to a fact that no additional adjustments are applied to building envelope or other parts of existing heating system in their case.

There are a plenty of financial support alternatives available. However, there is an offer that seems especially interesting while trying to reduce air pollution generated by heating of single family houses. The offer deals with the programme called Czyste Powietrze [en. The Clean Air Programme] (The Clean Air, 2018). The programme is offered by Polish Ministry for Environment together with the Fund for Environmental Protection and Water Governance (NFOŚiGW). It was started in 2018 and it will remain available til 2029. The programme extends previous tax-related initiatives aimed at the promotion of environmentally friendly improvements in single family houses. The improvements may deal with the replacement of obsolete boilers, the improvement of thermal properties of building envelope components as well as the installation of renewable energy sources and mechanical ventilation with heat recovery. The programme covers projects with qualified investment cost range from 7,000.00 PLN (about 1,650.00 EUR) to 53,000.00 PLN (about 12,350.00 EUR). Financial support deals with both a non-returnable subsidy and a loan that may even cover the remaining investment costs. Upper limits of shares for a subsidy and a preferential loan depends on average household income per capita. The share of a dotation ranges from even $90 \%$ for the poorest households to $10 \%$ for the richest households while the share of a preferential loan ranges from $70 \%$ to $30 \%$, respectively. Note that preferential loan expresses actual input of a programme beneficiary plus possible interest. The interest is about $2.6 \%$ as for the 15th of March 2019 and there are as much as 180 monthly instalments. The regress of a dotation share makes the programme especially well suited for needs of very poor households.

It is evident that, due to investment costs, only one of dominating alternatives, namely split heat pump Hp, as well as all medium dominance hierarchy level alternatives qualify for financing provided by the programme in the 
considered case. The remaining alternatives usually don't qualify for the programme due to too low $(\mathrm{Cf}, \mathrm{Ce})$ or too high (Hs) investment costs. Note also that actual investment costs for hard coal class 5 boiler (C5) make this alternative qualified to the programme directly without a need for provide any adjustments to building and other parts of heating system. Assessed beneficiary inputs required by the programme are presented in Table 2.

Table 2. Financial input of a beneficiary of the Clean Air programme [PLN] (source: own work)

\begin{tabular}{|c|c|c|c|c|c|c|}
\hline $\begin{array}{c}\text { Average income } \\
{[\text { PLN per capita] }}\end{array}$ & $\begin{array}{c}\text { Loan share } \\
{[\%]}\end{array}$ & $\mathrm{C}^{*}$ & $\mathrm{Ng}$ & $\mathrm{Bm}$ & $\mathrm{C5}$ & $\mathrm{Hp}$ \\
\hline 600 & 10 & 700.00 & $2,300.00$ & $2,400.00$ & $2,700.00$ & $5,000.00$ \\
\hline $601-800$ & 20 & $1,400.00$ & $4,600.00$ & $4,800.00$ & $5,400.00$ & $10,000.00$ \\
\hline $801-1,000$ & 30 & $2,100.00$ & $6,900.00$ & $7,200.00$ & $8,100.00$ & $15,000.00$ \\
\hline $1,001-1,200$ & 40 & $2,800.00$ & $9,200.00$ & $9,600.00$ & $10,800.00$ & $20,000.00$ \\
\hline $1,201-1,400$ & 50 & $3,500.00$ & $11,500.00$ & $12,000.00$ & $13,500.00$ & $25,000.00$ \\
\hline $1,401-1,600$ & 60 & $4,200.00$ & $13,800.00$ & $14,400.00$ & $16,200.00$ & $30,000.00$ \\
\hline over 1,600 & 70 & $4,900.00$ & $16,100.00$ & $16,800.00$ & $18,900.00$ & $35,000.00$ \\
\hline
\end{tabular}

${ }^{*}$ unacompanied hard coal class 5 boiler application

Note that the absolute lower limit for the highest user input category i.e. 1,600.00 PLN corresponds roughly to an average income in Poland in 2017 (GUS, 2018, p. 165). The offer thus seems to favour people with a rather slim wallet. On the other hand, percentage basis of subsidy and loan calculations promotes the application of advanced and expensive cost alternatives. Results presented in Table 2 show that only a standalone application of a hard coal class 5 boiler (C5) is offered, across all considered user income ranges, at investment cost comparable to full investment cost of standalone application of the internediate dominance hierarchy level alternatives $\mathrm{Ng}$ and $\mathrm{Bm}$. On the other hand, loan payment rules make each complex alternative interesting for a perspective user. This is because a real instalment level is very low. For example, Table 3 presents the estimation of initial (and average) instalments for current annual lending rate equal to $2.6 \%$ (as for the $15^{\text {th }}$ March 2019).

Table 3. The assessment of initial (and average) instalments according to the Clean Air programme rules [PLN] (source: own work)

\begin{tabular}{|c|c|c|c|c|c|}
\hline $\begin{array}{c}\text { Average income } \\
\text { [PLN per capita] }\end{array}$ & $\mathrm{C5}^{*}$ & $\mathrm{Ng}$ & $\mathrm{Bm}$ & $\mathrm{C} 5$ & $\mathrm{Hp}$ \\
\hline \multirow{2}{*}{600} & 5.41 & $\begin{array}{c}17.76 \\
(4.65)\end{array}$ & $\begin{array}{c}18.53 \\
(15.28)\end{array}$ & $\begin{array}{c}20.85 \\
(17.94)\end{array}$ & $\begin{array}{c}38.61 \\
(33.22)\end{array}$ \\
\hline \multirow{2}{*}{$601-800$} & 10.81 & 35.52 & 37.07 & 41.70 & 77.22 \\
& $(9.30)$ & $(30.57)$ & $(31.90)$ & $(35.88)$ & $(66.45)$ \\
\hline \multirow{2}{*}{$801-1,000$} & 16.22 & 53.28 & 55.60 & 62.55 & 115,83 \\
& $(13.95)$ & $(45.85)$ & $(47.84)$ & $(53.82)$ & $(99.67)$ \\
\hline \multirow{2}{*}{$1,001-1,200$} & 21.62 & 71.04 & 74.13 & 83.40 & 154.44 \\
& $(18.61)$ & $(61.13)$ & $(63.79)$ & $(71.77)$ & $(132.90)$ \\
\hline \multirow{2}{*}{$1,201-1,400$} & 27.03 & 88.81 & 92.67 & 104.25 & 193.06 \\
& $(23.26)$ & $(76.42)$ & $(79.74)$ & $(89.71)$ & $(166.12)$ \\
\hline \multirow{2}{*}{$1,401-1,600$} & 32.43 & 106.57 & 111.20 & 125.10 & 231,67 \\
& $(27.91)$ & $(91.70)$ & $(95.69)$ & $(107.65)$ & $(199.35)$ \\
\hline \multirow{2}{*}{ over 1,600 } & 37.84 & 124.33 & 129.73 & 145.95 & 270.28 \\
& $(32.56)$ & $(106.98)$ & $(111.63)$ & $(125.59)$ & $(232.57)$ \\
\hline
\end{tabular}

${ }^{*}$ mere hard coal class 5 boiler application

Financial situation differs among single family house owners who may be interested in taking advantage of the Clean Air programme. Therefore, to make a comprehensive analysis of practical availability of considered alternatives, average instalments were divided into 3 categories: average instalments which don't exceed 50.00 PLN, average instalments which exceed 50.00 PLN but don't exceed 100.00 PLN, and average instalments that exceed 100.00 PLN. The categories were then applied to express financial capabilities of poor, average and rich households, respectively. It was assumed for the purpose of presented analysis that income per capita doesn't exceed 800.00 PLN in poor households, 1600.00 PLN in average households and exceeds 1,600.00 PLN in rich households. Instalment levels adequate to capability of considered household groups are expressed in Table 3 by means of different cell 
backgrounds. White, light grey and dark grey backgrounds indicate the cases of affordable instalment levels for poor, average and rich households, respectively.

Data gathered in Table 3 confirm that the programme promotes the application of the dominating alternative, namely a split heat pump (Hp) in case of the poorest households (income per capita at 600.00 PLN or less). They must be capable of paying a monthly instalment at about 39.00 PLN (33.00 PLN on average), however. The alternative is also promoted among the average households (income per capita at 801.00 PLN - 1000.00 PLN) which should be able to afford the payment of a monthly instalment at about 116.00 PLN (100.00 PLN on average) as well as among rich families which have to pay a monthly instalment of about 270.00 PLN (233.00 PLN on average).

Significantly lower monthly instalments than in the case of a split heat pump (Hp) make the remaing alternatives attainable for almost all kinds of considered households with one exception. The exception deals with practical availability of complete hard coal class 5 boiler (C5) implementation in the case of richest average households. Monthly instalments are especially lower in the case of a mere application of the aforementioned alternative.

\section{Conclusions}

Air quality in Polish urbanized spaces during winter is very low. Heating of single family buildings by means of mass application of obsolete hard coal boilers seems to constitute one of the most important causes for poor air quality. Several possible means to mitigate this problem were discussed in the paper. Both the introduction of enhancements to the existing devices as well as the replacement of existing devices was considered in this regard. Poor economic situation of Polish households was also taken into account.

It was finally proven that limited financial resources of single family house owner may nevertheless help to considerably limit low pollution emission. A relatively low cost enhancement of furnace of existing hard coal boiler may be applied in this regard. However, the demanding environmental regulations make this relatively environmentally efficient alternative rather short-term. If the alternative is unavailable for technical reasons or one seeks more durable solutions there are also other options available. They deal with the replacement of the original device by boiler which uses other fuel e.g. natural gas or more energy safe biomass. The application of such boliers is neverthless significantly more expensive. As a result the boilers become attainable to a smaller number of single family house owners only. The severely limited financial resources of most single family house owners not only inhibit the application of renewable energy solutions but even make the owners incapable of implementing upgrade to hard coal class 5 boilers. This is why external financial support should be applied to implement environmentally friendly heating systems.

To enhance the existing financial support tools the Clean Air governmental programme was recently developed in Poland. Results of a sample analysis confirm possible advantageous effects of the programme with regard to widening the availability of environmentally friendly heating for single family house owners. This is because the programme enhances financial capability of the owners which facilitates the replacement of obsolete technologies with comprehensive modern solutions. Solutions of such a kind include both the replacement of utilised heat sources and adequate adjustments to building installations and building envelope. Although some - especially cheaper - renewable energy alternatives become also attainable, it seems that the programme should be enhanced to promote renewable energy more efficiently.

All in all presented results confirm that own financial resources of single family house owners and financial support programmes are capable of providing complementary means for the immediate and effective reduction of low pollution emission in Polish cities. The supporting programmes, and especially the Clean Air programme, also considerably help to reduce or even eliminate one of fundamental causes for poor air quality, namely energy poverty. However, more efforts with regard to the promotion of the ideas that lay behind programmes of such a kind are still needed. Popularisation of knowledge about rules for proper usage of heating devices will also help in the reduction of low air pollutant emission a lot.

\section{Acknowledgements}

The work was financed by a subsidy for scientific research provided by AGH UST, Cracow, Poland.

\section{References}

Birol, F. (2007). Energy economics: A place for energy poverty in the agenda?. Energy Journal, 28(3), 1-6. https://doi.org/10.5547/ISSN0195-6574-EJ-Vol28-No3-1

Clean heating. (2018). Modernizacja kotta zasypowego [Retrofitting of a hard coal batch boiler]. Portal Czyste Ogrzewanie [Clean Heating webportal]. Retrieved from https://www.gov.pl/web/energia/elektromobilnosc-w-polsce

Concise yearbook 2018. (2019). Household income and consumption expenditure. Concise statistical yearbook of Poland 2018. GUS [Statistics Poland]. Warsaw. 165 p. 
European Parliament, \& Council of the European Union. (2015). COMMISSION REGULATION (EU) 2015/1189 of 28 April 2015 implementing Directive 2009/125/EC of the European Parliament and of the Council with regard to ecodesign requirements for solid fuel boilers. Official Journal of the European Union, 193/100, 21.7.2015.

GUS. (2018). Concise statistical yearbook of Poland. Statistics Poland, Warsaw.

Hewalex. (2019). PCCO Split 20kW. Portal firmy Hewalex [The Hevalex enterprise webportal]. Retrieved from https://www.hewalex.pl/oferta/pompy-ciepla-powietrzewoda-do-co-cwu-chlodzenia/pompa-ciepla-powietrzewoda-pcco-spli t-20-kw.html

Magical Cracow. (2016). Wszystko o bezpłatnej komunikacji w czasie smogu. Portal Magiczny Kraków [Magical Cracow webportal]. Retrieved from https://www.gov.pl/web/energia/elektromobilnosc-w-polsce

Polish Government. (2016). Elektromobilność w Polsce [The electro-mobility in Poland]. Portal Rządu Rzeczypospolitej Polskiej [Polish Government web portal]. Retrieved from https://www.gov.pl/web/energia/elektromobilnosc-w-polsce

Primc, K., Slabe-Erker, R., \& Majcen, B. (2019). Constructing energy poverty profiles for an effective energy policy. Energy Policy, 128, 727-734. https://doi.org/10.1016/j.enpol.2019.01.059

The Clean Air. (2018). Portal programu Czyste Powietrze [Web page for the Clean Air programme]. MOŚ RP [Polish Ministry for Environment]. Retrieved from http://powietrze.mos.gov.pl/

Wesołowska, E. (2018). Polskie filtry zwalcza smog [Polish filters will combat a killer fog]. Portal Wgospodarce [Wgospodarce webportal]. Retrieved from http://wgospodarce.pl/informacje/46604-polskie-filtry-zwalcza-smog 